\title{
OPEN Gallium oxide nanowires for UV detection with enhanced growth and material properties
}

\author{
Badriyah Alhalaili, ${ }^{1,4}$, Ryan James Bunk ${ }^{2,4}$, Howard Mao², Hilal Cansizoglu², \\ Ruxandra Vidu ${ }^{2,3}$, Jerry Woodall2 \& M. Saif Islam²
}

In the last decade, interest in the use of beta gallium oxide $\left(\beta-\mathrm{Ga}_{2} \mathrm{O}_{3}\right)$ as a semiconductor for high power/high temperature devices and deep-UV sensors has grown. $\mathrm{Ga}_{2} \mathrm{O}_{3}$ has an enormous band gap of $4.8 \mathrm{eV}$, which makes it well suited for these applications. Compared to thin films, nanowires exhibit a higher surface-to-volume ratio, increasing their sensitivity for detection of chemical substances and light. In this work, we explore a simple and inexpensive method of growing high-density gallium oxide nanowires at high temperatures. Gallium oxide nanowire growth can be achieved by heating and oxidizing pure gallium at high temperatures $\left(\sim 1000^{\circ} \mathrm{C}\right)$ in the presence of trace amounts of oxygen. This process can be optimized to large-scale production to grow high-quality, dense and long $\mathrm{Ga}_{2} \mathrm{O}_{3}$ nanowires. We show the results of morphological, structural, electrical and optical characterization of the $\beta-\mathrm{Ga}_{2} \mathrm{O}_{3}$ nanowires including the optical bandgap and photoconductance. The influence of density on these $\mathrm{Ga}_{2} \mathrm{O}_{3}$ nanowires and their properties will be examined in order to determine the optimum configuration for the detection of UV light.

Technology involving the development of ultra-wide bandgap semiconductors such as $\beta-\mathrm{Ga}_{2} \mathrm{O}_{3}$ has received considerable attention, its unique combination of chemical stability and wide band gap facilitates diverse UV applications in nanoscale electronics and optoelectronics ${ }^{1}$ such as solar UV monitoring, astronomy, communications, and detection of missiles. Recently, there has been significant interest in UV photodetectors (PDs) because of civil, military, environmental, and industrial market needs to improve UV instrumentation that operate in extremely harsh environments. Therefore, many studies have been proposed to fabricate UV photodetectors with specialized features to both survive in harsh environments and detect the UV region of the spectrum while remaining blind to visible wavelengths.

$\beta-\mathrm{Ga}_{2} \mathrm{O}_{3}$ is an ideal candidate for visible-blind UV-light sensors, particularly for power electronics, solar-blind UV detectors, and device applications in harsh environments ${ }^{2,3}$. In particular, nanowires have high surface area, small diameter, internal scattering, and high photoconductive gain, which can allow UV photodetectors based on them to achieve high responsivity. Furthermore, nanowires can minimize the side effects of lattice and thermal mismatch during the growth process, which simplifies the production of high performance devices ${ }^{4}$. Additionally, one of the benefits of using nanowires is the ability to enhance light absorption and confine light to increase photosensitivity ${ }^{5}$. For example, the presence of metal nanoparticles with size less than $10 \mathrm{~nm}$ at the surface of nanowires induces localized surface plasmons which can be excited and enhanced Rayleigh scattering ${ }^{6}$. Moreover, nanowire photodetectors offer the possibility to isolate optical absorption and carrier transport paths ${ }^{7,8}$.

In this work, the high sensitivity, simple and inexpensive fabrication process demonstrated by our $\beta-\mathrm{Ga}_{2} \mathrm{O}_{3}$ nanowire UV photodetector makes it promising for use in deep-ultraviolet detection applications. The $\beta-\mathrm{Ga}_{2} \mathrm{O}_{3}$ nanowires for UV photodetection were prepared by thermal oxidation at $1000{ }^{\circ} \mathrm{C}$ using an $\mathrm{Ag}$ catalyst. We demonstrate the structure and morphology of the nanowires in addition to performing optical and electrical characterization of the nanowire's sensing properties.

\footnotetext{
${ }^{1}$ Nanotechnology and Advanced Materials Program, Kuwait Institute for Scientific Research, Kuwait City, Kuwait. ${ }^{2}$ Department of Electrical and Computer Engineering, University of California, Davis, Davis, USA. ${ }^{3}$ Faculty of Materials Science and Engineering, University of Politehnica of Bucharest, Bucharest, Romania. ${ }^{4}$ These authors contributed equally: Badriyah Alhalaili and Ryan James Bunk. ${ }^{\bowtie}$ email: bhalaili@kisr.edu.kw
} 


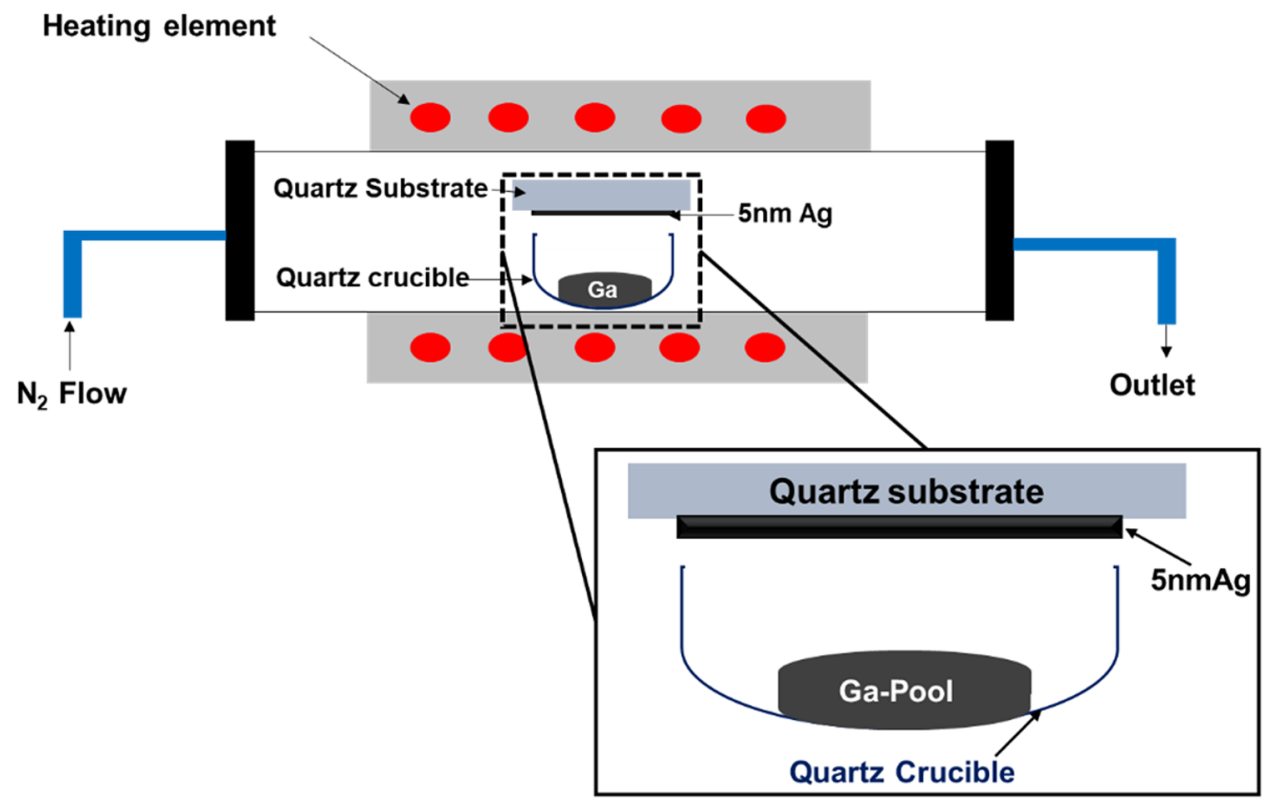

Figure 1. Schematic illustration of the UV photodetector fabrication technique.

\section{Methods}

First, quartz substrates were cleaned with acetone and isopropyl alcohol, rinsed with deionized water, and dried with a stream of nitrogen gas. The quartz substrates used in this experiment were $500 \mu \mathrm{m}$ thick and $15 \mathrm{~mm}$ in diameter. A silver thin film $5 \mathrm{~nm}$ thick was deposited on the cleaned samples using a Lesker sputtering system. Sample not coated with Ag films were given the same cleaning treatment.

Afterwards, the samples were re-cleaned with acetone and isopropyl alcohol, rinsed with deionized water, and then dried with an $\mathrm{N}_{2}$ gun to remove contaminants immediately prior to growth. Then, the samples were loaded into a quartz crucible which was placed into an OTF-1200X-50-SL horizontal alumina tube furnace made by MTI Corporation. The samples were exposed to temperatures of $800^{\circ} \mathrm{C}$ and $1000^{\circ} \mathrm{C}$ for $60 \mathrm{~min}$. Heating occurred in a $20 \mathrm{sccm}$ flow of nitrogen at atmosphere pressure. The background oxygen concertation was determined to be from 100 to $200 \mathrm{ppm}$ using a downstream oxygen sensor. Samples were positioned above the gallium, such that the silver faced the gallium pool. The distance between the substrate and the gallium pool was about $10 \mathrm{~mm}$. To minimize the potential for cross contamination, samples with silver and without silver were grown in different runs with dedicated crucibles. The quartz crucible was inserted inside the furnace, and the furnace was sealed and continuously flowed with nitrogen during growth. After the growth process, the electrical contacts were patterned on the top of the nanowires. A shadow mask was used to pattern $5 \mathrm{~nm} \mathrm{Cr}$ and $50 \mathrm{~nm}$ Au on the surface of $\mathrm{Ga}_{2} \mathrm{O}_{3}$ Nanowires, deposited using a Lesker sputtering system. In addition, we examined the use of a $10 \times 10 \mathrm{~mm}$ gold mesh as an external contact with $0.064 \mathrm{~mm}$ thickness. Figure 1 shows the growth apparatus of the $\mathrm{Ga}_{2} \mathrm{O}_{3}$ nanowires by $\mathrm{Ag}$ catalyst.

\section{Results and discussion}

Scanning electron microscopy (SEM). To explore the growth mechanism of $\mathrm{Ga}_{2} \mathrm{O}_{3}$ nanowires, $\mathrm{Ga}_{2} \mathrm{O}_{3}$ was grown with and without a $5 \mathrm{~nm} \mathrm{Ag}$ thin film as a catalyst at $1000{ }^{\circ} \mathrm{C}$. Interestingly, the morphology of the nanowires grown on bare quartz was different from that of the nanowires coated with $5 \mathrm{~nm} \mathrm{Ag}$. The Ag catalyst is found to enhance nanowire growth rate as well as increase the density of nucleation sites. SEM images (Fig. 2) showed that the density and size of the nanowires were much larger on Ag-coated samples after growth. Additionally, a homogeneous coating of $\mathrm{Ga}_{2} \mathrm{O}_{3}$ was observed under certain conditions and denser nanowires were grown at $1000^{\circ} \mathrm{C}$ in the presence of $5 \mathrm{~nm} \mathrm{Ag}$ compared to those grown without Ag. The Ag catalyst appears to play a role in reducing the diameters of the nanowires from 150-270 nm in the case of Ag-free growth to 120-160 nm when Ag was present. Even though denser, longer and thinner nanowires were observed by SEM imaging, no Ag NPs were seen at the tip or on the surface of $\mathrm{Ga}_{2} \mathrm{O}_{3}$ nanowires. Consequently, other characterization techniques were performed to investigate the morphology and elemental composition of these nanowires.

XRD characterization. XRD was performed with a Panalytical XPert PRO Diffractometer (Malvern Panalytical, Netherlands). Figure 3 shows the XRD patterns of the $\mathrm{Ga}_{2} \mathrm{O}_{3}$ nanowire on quartz substrates oxidized at $1000{ }^{\circ} \mathrm{C}$. The results are consistent with polycrystalline $\beta-\mathrm{Ga}_{2} \mathrm{O}_{3}$ results in the Joint Committee on Powder Diffraction Standards (JCPDS) card \# 11-370. All major peaks of the $\beta-\mathrm{Ga}_{2} \mathrm{O}_{3}$ phase are seen to be present in the diffraction data, which strongly indicates the nanowires are $\beta-\mathrm{Ga}_{2} \mathrm{O}_{3}$. The apparent random orientation does not necessarily indicate the crystal growth direction is random, but more likely the nanowires are not self-aligned. 


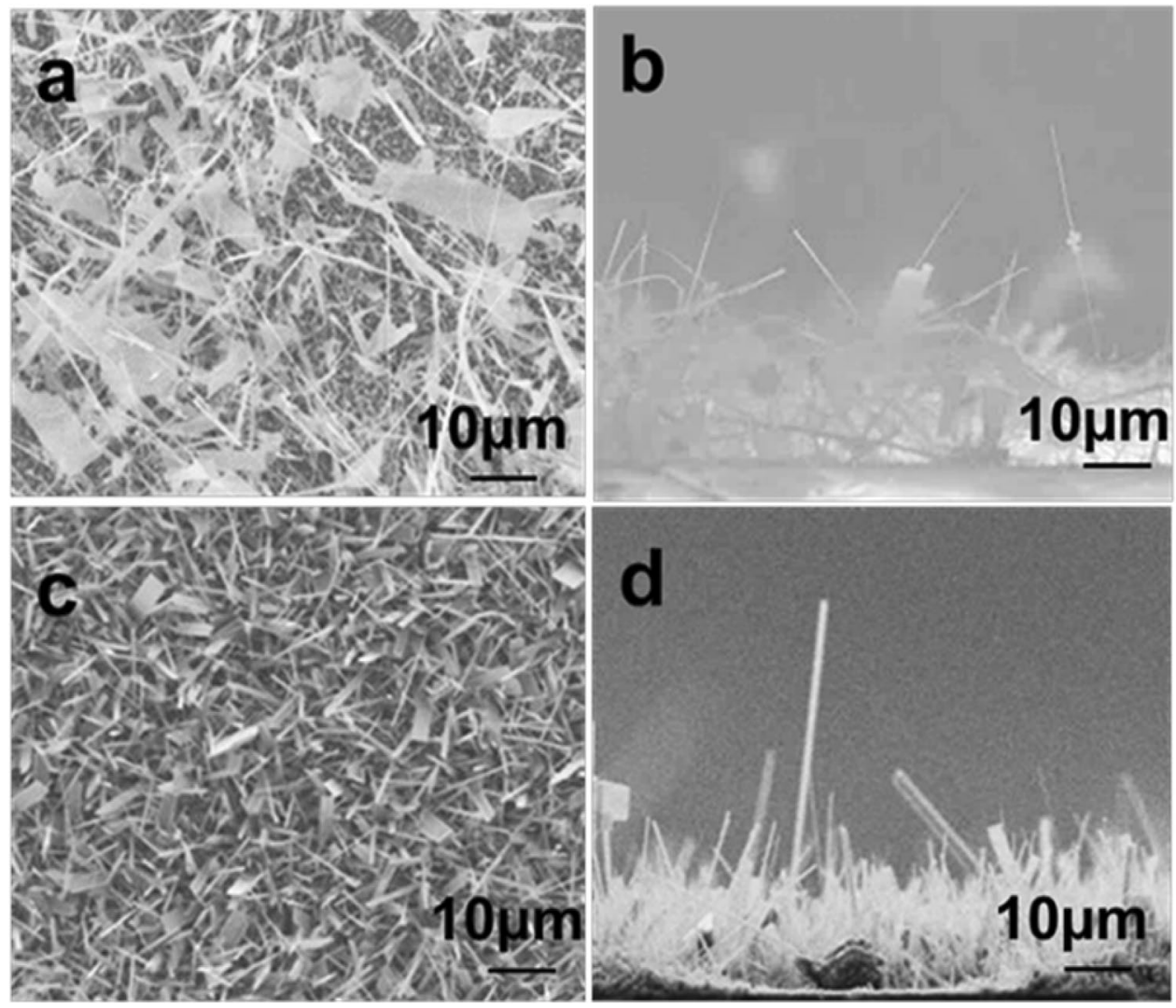

Figure 2. $\mathrm{Ga}_{2} \mathrm{O}_{3}$ nanowire grown at $1000{ }^{\circ} \mathrm{C}$. (a,b) Top and side views of $\mathrm{Ga}_{2} \mathrm{O}_{3}$ on a quartz substrate, respectively. (c,d) Top and side views of $\mathrm{Ga}_{2} \mathrm{O}_{3}$ on quartz catalyzed by $5 \mathrm{~nm} \mathrm{Ag}$, respectively. Longer and denser NWs were achieved when Ag films are present on the sample before growth.

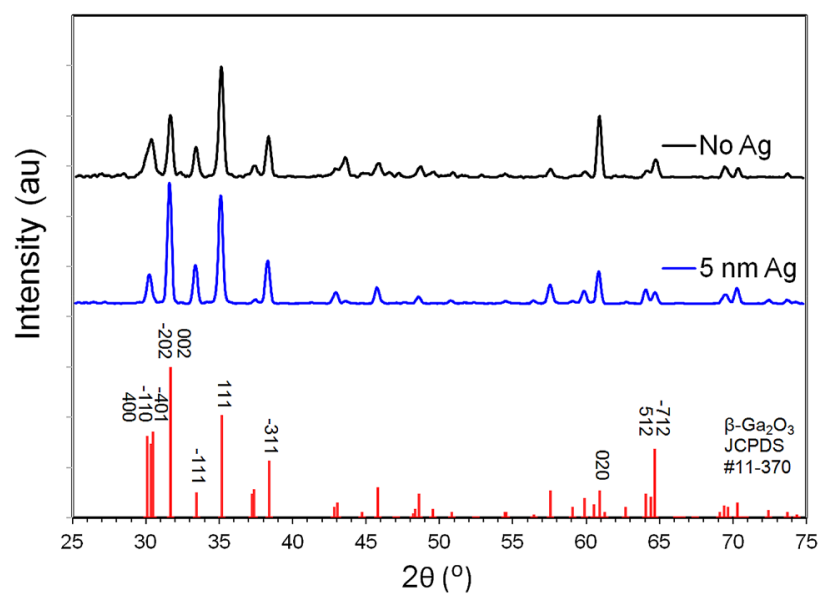

Figure 3. $\theta-2 \theta \mathrm{x}$-ray diffraction (XRD) pattern, indexed in comparison to JCPDS $11-370$, for $\beta-\mathrm{Ga}_{2} \mathrm{O}_{3}$ grown at $1000{ }^{\circ} \mathrm{C}$.

However, it is noticeable that in the No Ag sample, the (020) peak is stronger and (002) peak weaker than random powder, and for the Ag sample it more closely follows a random pattern.

Optical characterization. A UV-VIS spectrophotometer (Ocean Optics HR4000CG-UV-NIR high resolution spectrometer) was used to measure the optical properties of the nanowires, such as transmission, reflection and absorption. To determine the bandgap of these nanowires, a plot of $(a h v)^{2}$ versus photon energy was made. The bandgap was assessed by translating the transmittance curve and then correlating the bandgap $\left(E_{g}\right)$ with equation ${ }^{9}$ 


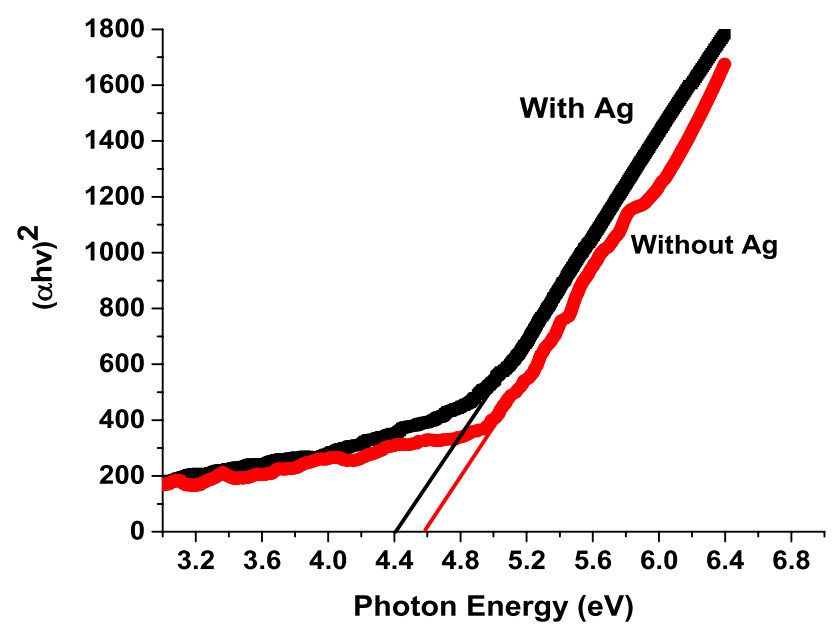

Figure 4. Plot of $(a h v)^{2}$ versus photon energy.

\begin{tabular}{|l|l|l|}
\hline Catalyst & Bandgap [eV] & Refs. \\
\hline $\mathrm{Ni}$ & 4.30 & 11 \\
\hline \multirow{2}{*}{$\mathrm{Au}$} & $4.7-4.8$ & 12 \\
\cline { 2 - 3 } & 4.56 & 13 \\
\hline None & 4.6 & \multirow{2}{*}{ This work } \\
\hline $5 \mathrm{~nm} \mathrm{Ag}$ & 4.4 & \\
\hline
\end{tabular}

Table 1. Previously reported bandgaps of $\beta-\mathrm{Ga}_{2} \mathrm{O}_{3}$ nanowires.

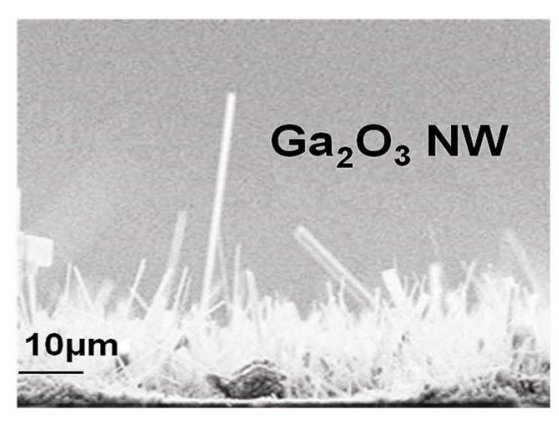

a

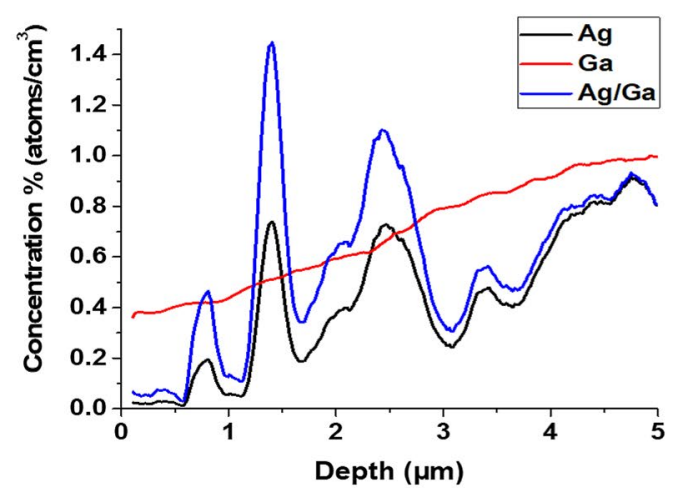

b

Figure 5. $\mathrm{Ga}_{2} \mathrm{O}_{3} \mathrm{NWs}$ on quartz substrate by $5 \mathrm{~nm} \mathrm{Ag}$ catalyst at $1000^{\circ} \mathrm{C}$. (a) SEM image. (b) SIMS profile. The SIMS was performed for nanowires from the tip to the base. As we go from the tip to the root of NWs, the concentration of Ag increases.

$$
[\alpha h v]^{2}=A\left(h v-E_{g}\right)
$$

where $E_{g}$ is the optical bandgap, A is a constant and $h v$ is the incident photon energy; $\alpha$ is the absorption coefficient. Figure 4. shows a plot of $(\alpha h v)^{2}$ versus photon energy. The bandgap of $\beta-\mathrm{Ga}_{2} \mathrm{O}_{3}$ nanowires with and without silver was found to be $4.6 \mathrm{eV}$ and $4.4 \mathrm{eV}$, respectively. Table 1 . shows previously reported results for the bandgap of $\beta-\mathrm{Ga}_{2} \mathrm{O}_{3}$ nanowires using different catalysts. Overall, the shift in the optical bandgap results which is about 0.2 , which is in good agreement with the shift of the optical band gap $\left(3.68 \mathrm{eV}\left(\mathrm{Ag} / \mathrm{Ga}_{2} \mathrm{O}_{3}\right)-3.85 \mathrm{eV}\right.$ $\left.\left(\mathrm{Ga}_{2} \mathrm{O}_{3}\right)\right)$ as reported previously ${ }^{10}$.

Secondary Ion Mass Spectrometry (SIMS). A SIMS profile analysis (Fig. 5) was performed to provide a better understanding of the composition of nanowires surface. The beam was incident normal to the surface of 

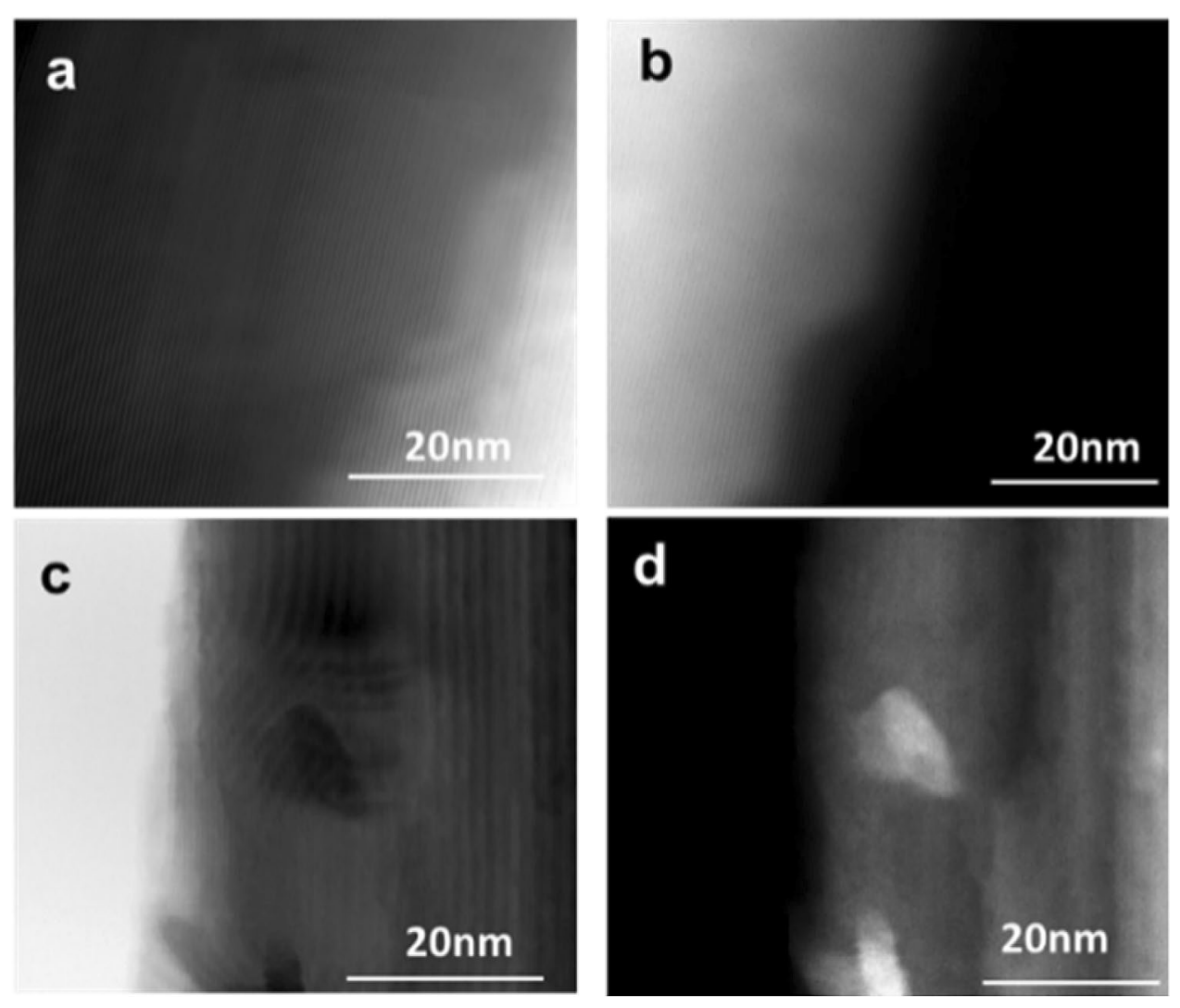

Figure 6. STEM images of $\mathrm{Ga}_{2} \mathrm{O}_{3}$ nanowire growth on quartz substrate at $1000^{\circ} \mathrm{C}$. (a) Bright field (BF) (b) high-angle annular dark-field (HAADF) STEM images of $\mathrm{Ga}_{2} \mathrm{O}_{3}$ nanowire without $\mathrm{Ag}$ catalyst. (c) Bright field (BF) (d) high-angle annular dark-field (HAADF) images of $\mathrm{Ag}$ NPs at the interface of $\mathrm{Ga}_{2} \mathrm{O}_{3}$ nanowire. The nanoparticle was bright due to $\mathrm{z}$-contrast.

the sample. Due to the spot size limitation of the SIMS spectrometer, it was difficult to perform a single nanowire depth profile from tip to the base of nanowire, so the results are an aggregate of many randomly oriented and distributed nanowires. While the curve for $\mathrm{Ga}$ is relatively smooth, the curve of Ag has distinct peaks, demonstrating nonuniform spatial distribution of $\mathrm{Ag}$ within the nanowire forest. The ratio of Ag-to-Ga signal intensity versus depth has proportional increase towards the quartz surface.

Scanning Transmission Electron Microscopy (STEM). Figure 6 shows a STEM image of bright field (BF) and high-angle annular dark-field (HAADF) of a $\mathrm{Ga}_{2} \mathrm{O}_{3}$ nanowire grown at $1000{ }^{\circ} \mathrm{C}$ on quartz (Fig. 6a,b) and on quartz coated with $5 \mathrm{~nm} \mathrm{Ag}$ (Fig. $6 \mathrm{c}$,d). The $\beta-\mathrm{Ga}_{2} \mathrm{O}_{3}$ nanowire, which was not exposed to Ag catalyst, has no particles on its surface. However, the $\beta-\mathrm{Ga}_{2} \mathrm{O}_{3}$ nanowire shows several NPs with diameters between $5-10 \mathrm{~nm}$ that decorate the surface. Due to the transfer technique, it is not possible to determine the root or the tip of the nanowire. Han et al. has shown similar TEM characterization of Ag NPs on the surface of $\mathrm{Ga}_{2} \mathrm{O}_{3}{ }^{10}$. Bright field showed dark NPs due to diffraction contrast, since the nanoparticles are crystalline. Also, HAADF was performed to capture the z-contrast of Ag NPs. The NPs appear much brighter despite their small size, which suggests that their atomic mass and density are significantly larger than the surrounding $\beta-\mathrm{Ga}_{2} \mathrm{O}_{3}$, which points to Ag.

High Resolution Transmission Electron Microscopy (HRTEM). To explore the presence of Ag on the surface of the grown $\mathrm{Ga}_{2} \mathrm{O}_{3}$ nanowires, a JEOL 2100F transmission electron microscope (TEM) was used to image $\mathrm{Ga}_{2} \mathrm{O}_{3}$ nanowires grown on a fused quartz substrate, without and with the presence of $\mathrm{Ag}$ as shown in Fig. 7. $\mathrm{Ga}_{2} \mathrm{O}_{3}$ nanowires without Ag catalyst show a smooth surface in HRTEM. However, $\mathrm{Ga}_{2} \mathrm{O}_{3}$ nanowire in the presence of Ag shows nanoparticles decorating the surface, with diameters between $2-5 \mathrm{~nm}$.

The JEOL 2100F TEM was also equipped with an energy-dispersive spectroscopy (EDS) profile system, which was used to analyze the composition of $\mathrm{Ga}_{2} \mathrm{O}_{3}$ nanowires grown on quartz (Fig. 8). It was further used to search for silver, which was detected but not seen in the SEM observation. The TEM images correspond to the elemental mapping for $\mathrm{Ga}, \mathrm{O}$ and $\mathrm{Ag}$. Although no Ag nanoparticles were visibly detected on the surface of the nanowire, the particles may be too small to produce a signal detectable to the EDS detector in the TEM due to the large interaction volume required by EDS for electron capture and x-ray emission. 

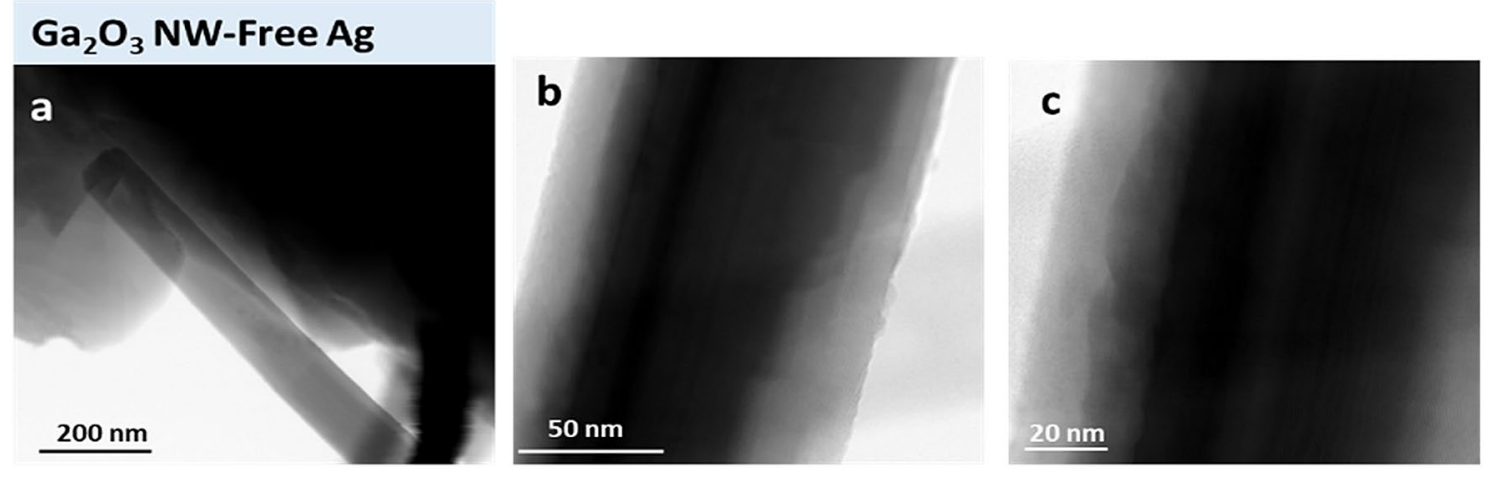

\section{$\mathrm{Ga}_{2} \mathrm{O}_{3} \mathrm{NW}-\mathrm{Ag}$ Catalyst}
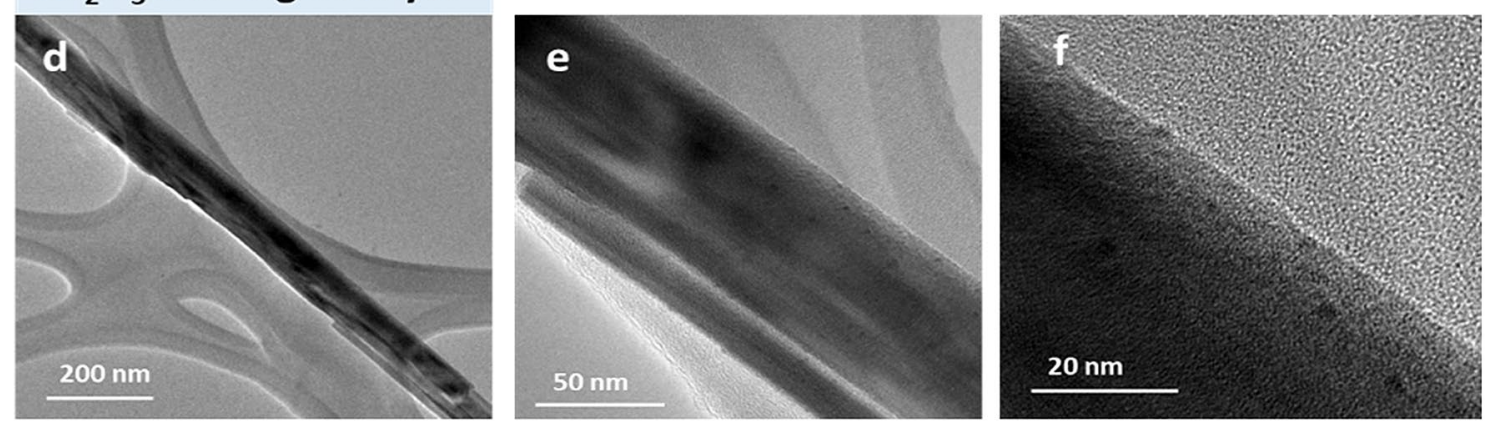

Figure 7. HRTEM images taken at different magnifications of single crystalline $\mathrm{Ga}_{2} \mathrm{O}_{3} \mathrm{NW}$ grown on fused quartz substrate. The top row shows images of single $\mathrm{Ga}_{2} \mathrm{O}_{3} \mathrm{NW}$ without the presence of $\mathrm{Ag}$ catalyst with scale bars at (a) $200 \mathrm{~nm}$, (b) $50 \mathrm{~nm}$ and (c) $20 \mathrm{~nm}$. Bottom row shows a $\mathrm{Ga}_{2} \mathrm{O}_{3} \mathrm{NW}$ grown in the presence of $\mathrm{Ag}$ catalyst with different scale bars at (c) $200 \mathrm{~nm}$, (d) $50 \mathrm{~nm}$ and (f) $20 \mathrm{~nm}$. Few nanoparticles were observed on the surface of $\mathrm{Ga}_{2} \mathrm{O}_{3} \mathrm{NW}$ as shown in (d) and (f).
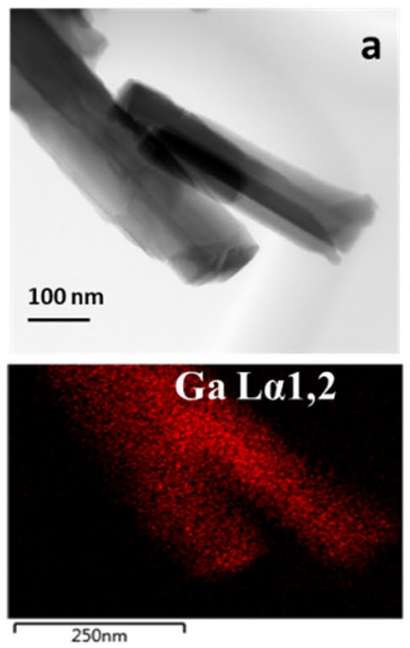

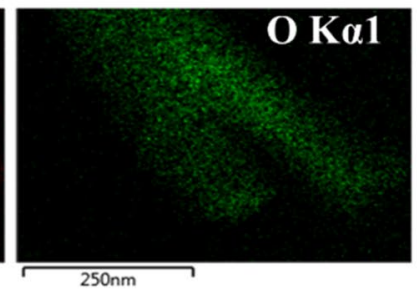

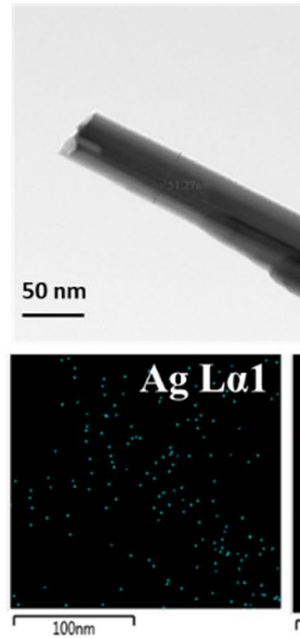

$100 \mathrm{~nm}$ b

\begin{tabular}{|c|c|}
\hline Element & Atomic \% \\
\hline $\mathbf{O}$ & 61.6 \\
\hline $\mathbf{G a}$ & 38.4 \\
\hline
\end{tabular}

\begin{tabular}{|c|c|}
\hline Element & Atomic $\%$ \\
\hline $\mathbf{O}$ & 60.6 \\
\hline $\mathbf{G a}$ & 39.4 \\
\hline $\mathbf{A g}$ & 0.0 \\
\hline
\end{tabular}

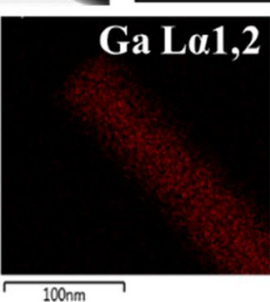

$100 \mathrm{~nm}$

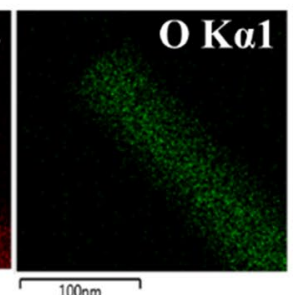

$100 \mathrm{~nm}$

Figure 8. HRTEM image and the corresponding EDS mapping of $\mathrm{Ga}_{2} \mathrm{O}_{3} \mathrm{NW}$ grown on quartz substrates (left) without the presence (right) in the presence of Ag catalyst.

Selective area diffraction pattern. Selective area diffraction patterns were also taken to better understand the crystal structure of the nanowires obtained with or without Ag catalyst. The low-symmetry of the monoclinic crystal structure of $\beta-\mathrm{Ga}_{2} \mathrm{O}_{3}$ makes interpretation of diffraction results difficult in general, so the analysis of the patterns was guided using the SingleCrystal TEM diffraction simulator from CrystalMaker. To identify the zone axis, the spacings between points and the angles were measured, and compared to different zone axes, as shown in Fig. 9:

From the XRD results in Fig. 3, it is known in advance that the crystal structure of the nanowires is $\beta-\mathrm{Ga}_{2} \mathrm{O}_{3}$, which serves as a starting point for interpretation. It can be seen that the diffraction spots in Fig. 9 are distinct 


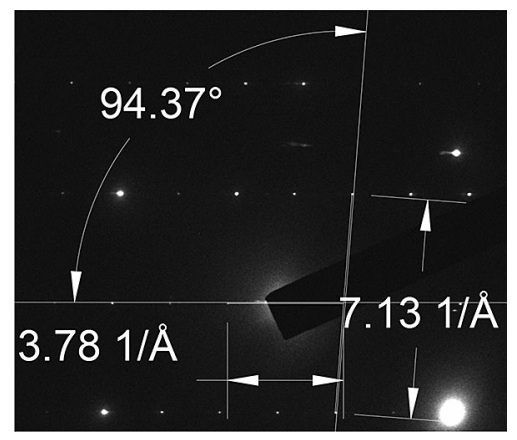

Figure 9. Measured angle and spacings for nanowire grown without Ag.

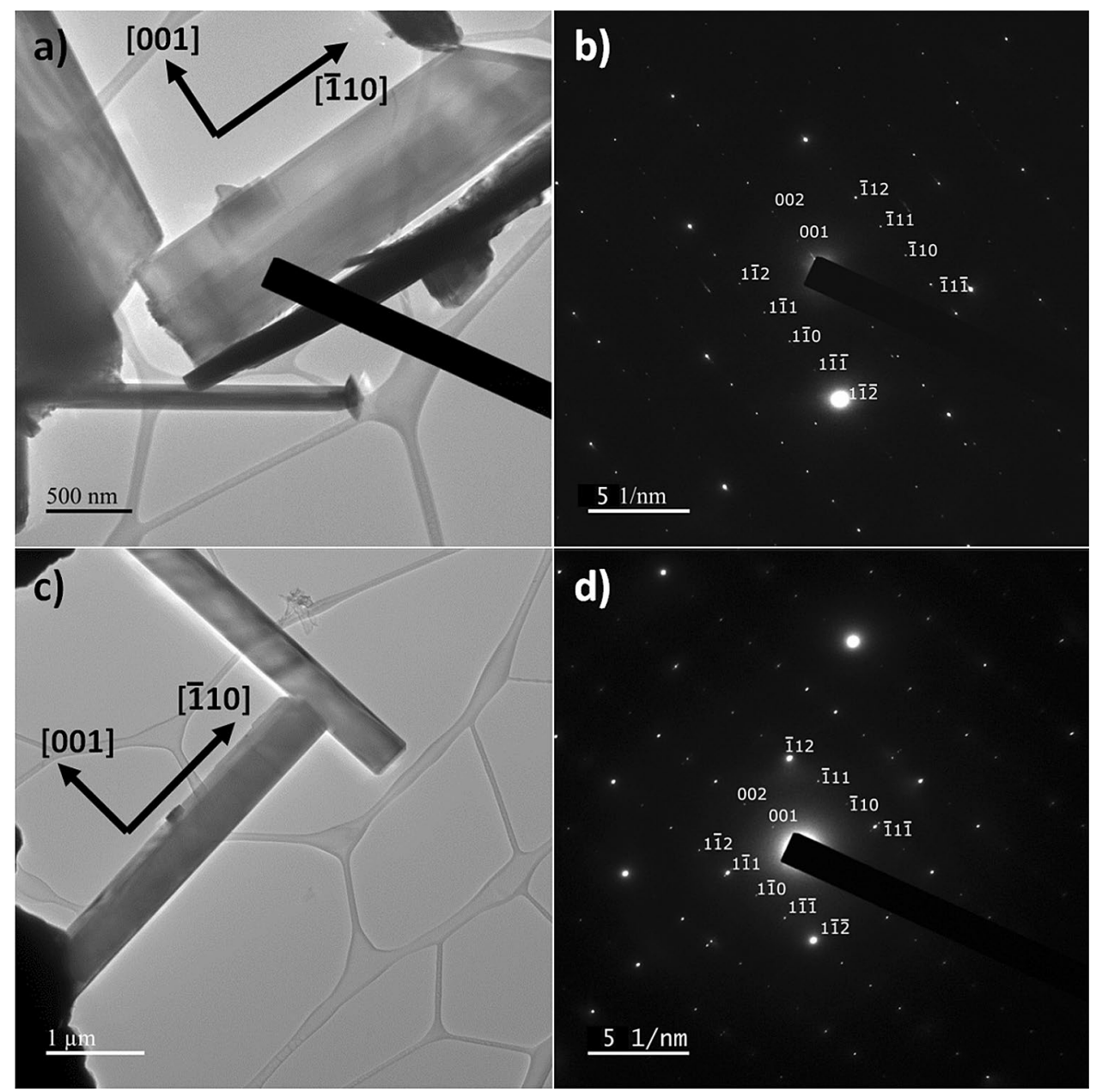

Figure 10. Indexed SAED pattern for $(\mathbf{a}, \mathbf{b})$ with $\mathrm{Ag}$ catalyst, $(\mathbf{c}, \mathbf{d})$ without $\mathrm{Ag}$ catalyst.

and sharp points, which strongly indicates the nanowires were single crystals. Using the lattice parameters of the $\beta-\mathrm{Ga}_{2} \mathrm{O}_{3}$ crystal, the pattern for various zone axes may be calculated. The result in Fig. 9 matches most similarly with the simulation for the [011] zone axis, with an angle of $94.05^{\circ}$, and a calculated [001] $\mathrm{d} / 2$ spacing of 3.5524 $1 / \AA$, and a calculated [-110] spacing of $6.79781 / \AA$. Based on this, the image may be indexed using the simulation as a guide. The results of this are shown in Fig. 10.

In both cases the growth direction is found to be the [-110] direction based upon the measured diffraction spacing, with the orthogonal direction as [001]. This would indicate the difference in the [020] and [002] peaks shown in Fig. 3, which were not due to a difference in the orientation of the nanowires, but some other factor instead. Both samples growth with Ag and without Ag showed the same orientation, indicating that the growth acceleration due to Ag catalyst does not impact the orientation of the resulting nanowires. Additionally, there 

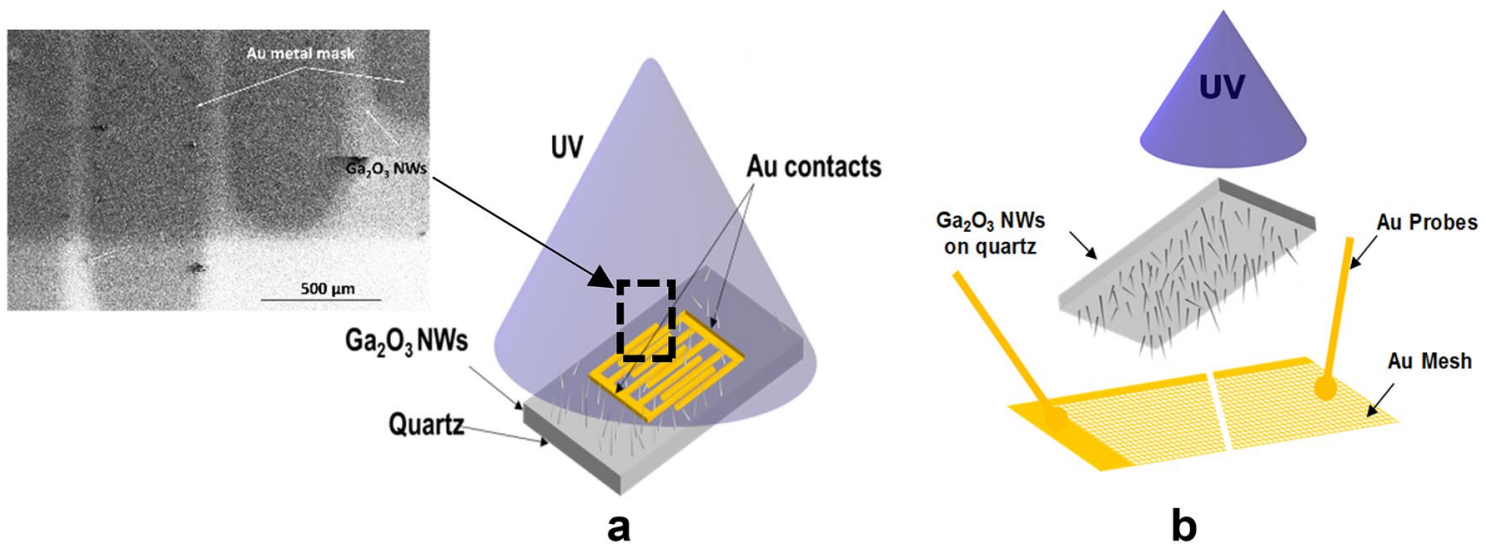

Figure 11. Schematic of $\mathrm{Au} / \beta-\mathrm{Ga}_{2} \mathrm{O}_{3} / \mathrm{Au}$ metal-semiconductor-metal (MSM) photoconductor on quartz. (a) Sputtered gold contacts. The distance between the circles probes is $3 \mathrm{~mm}$. Top-left SEM image of Au contacts at the surface of $\mathrm{Ga}_{2} \mathrm{O}_{3}$ NWs. (b) Au mesh gold contacts.

were no diffraction spots that could not be accounted for in this analysis, further indicating that not only were the nanowires single crystal, there are no twins or secondary $\mathrm{Ga}_{2} \mathrm{O}_{3}$ phases.

Electrical characterization. Photocurrent and dark current measurements. A Au/ $\beta-\mathrm{Ga}_{2} \mathrm{O}_{3} / \mathrm{Au}$ metalsemiconductor-metal (MSM) photoconductor (Fig. 11a) was fabricated to investigate the electronic conductivity of the grown $\beta-\mathrm{Ga}_{2} \mathrm{O}_{3}$. The surface of $\mathrm{Ga}_{2} \mathrm{O}_{3}$ NWs was attached to a shadow mask to deposit $\mathrm{Au} / \mathrm{Cr}$ contacts by using a Lesker sputtering system. For the electrical measurements, a custom probe station attached to a Keithley 2400 SMU was used and UV illumination was from a broadband Dymax Bluewave75 UV lamp (280-450 nm) (Dymax Corporation, USA). In addition, we performed other selective wavelengths from Newport monochromator with XeHg lamps.

The current-voltage $(I-V)$ characteristics were measured in dark conditions and under UV illumination for a MSM structure with and without an Ag catalyst at $10 \mathrm{~V}$ (Fig. 12). The MSM back-to-back Schottky diodes under UV illumination with a light intensity of $15 \mathrm{~W} / \mathrm{cm}^{2}$ showed results comparable to the dark current. Due to the surface plasmonic effect of Ag NPs at the surface of $\mathrm{Ga}_{2} \mathrm{O}_{3} \mathrm{NWs}$, the absorption of photon is highly enhanced ${ }^{14}$, leading to more photoexcited carriers transport and collection at the contacts (Fig. 12c,d). Additionally, the results showed that $\mathrm{Ga}_{2} \mathrm{O}_{3}$ on quartz with a $5 \mathrm{~nm} \mathrm{Ag}$ catalyst improves the photocurrent response to the broad spectrum UV source. The results reveal that the steady photocurrent of $\mathrm{Ag} / \mathrm{\beta}_{-}-\mathrm{Ga}_{2} \mathrm{O}_{3}$ (Fig. 12c) was three order of magnitude higher than that of the photocurrent of $\mathrm{Ag}$-free $/ \beta-\mathrm{Ga}_{2} \mathrm{O}_{3}$ (Fig. 12a). Hence, silver as a catalyst plays a critical role in improving the electrical properties of the $\beta-\mathrm{Ga}_{2} \mathrm{O}_{3}$ nanowires. The photodetection mechanism of the $\beta-\mathrm{Ga}_{2} \mathrm{O}_{3}$ nanowire is credited to different aspects that mainly include the incident light absorption, carrier photogeneration and carrier transport and surface oxygen adsorption and desorption process ${ }^{15}$.

The metal contacts deposition method has a large impact on the dark current and photocurrent. Even though $\mathrm{Ag} / \mathrm{Ga}_{2} \mathrm{O}_{3}$ was sputtered with gold contacts shows high current response under illumination, it showed a large increase in the dark current as well (Fig. 12a,c). The major disadvantage of sputtering gold contacts is the induction of a damage that effects Fermi level pinning and hence the electrical measurements. This is due to the interfacial disorder of oxygen or Ag atoms vacancies ${ }^{16}$. Therefore, Au mesh contacts were used to avoid the consequence of sputtering technique as shown Fig. 11b. With using this technique, the results have been improved (Fig. 12b,d). The presence of Ag NPs at the surface was found to increase both photocurrent and dark current for sputtered contacts, however for mesh contacts it produced a substantial decrease in dark current. This could be due to an interaction between the Ag and deposited Au which produced a large leakage, but would not occur for mechanically applied mesh contacts.

The presence of Ag NPs at the surface plays a critical role in reducing the dark current of $\mathrm{Ga}_{2} \mathrm{O}_{3}$ on quartz compared to the one without Ag catalyst when mesh contacts are used, as shown in the Fig. 12. The results indicated that a covering of $\mathrm{Ag}$ nanoparticles on the $\mathrm{Ga}_{2} \mathrm{O}_{3}$ surface of devices can both decrease the dark current, and increase the photocurrent, both of which are beneficial. In addition, larger photocurrent can be observed for $\mathrm{Ga}_{2} \mathrm{O}_{3}$ on quartz decorated with Ag NPs. For dark current, a Schottky barrier formed at the interface between $\mathrm{Ag}$ and $\mathrm{Ga}_{2} \mathrm{O}_{3}$ due to the difference of the work function, where $\mathrm{Ag}$ NPs and $\mathrm{Ga}_{2} \mathrm{O}_{3}$ have the equal Fermi energy level. However, the positively charged Ag NPs depleted the carriers near the nanowires surface. This may deplete carriers in the nanowires in the absence of light, leading to higher dark resistivity in the material and lower dark current.

The I-V measurement of the photocurrent for the photodetector was measured at different selected wavelengths such as 250,260 and $280 \mathrm{~nm}$ with $1 \mathrm{~mW}$ LED lamps to evaluate the device performance for the detection of deep UV light with high input power (Fig. 13a). interestingly, the photodetection response with Ag catalysts was improved by almost two order of magnitude. The ratio of photocurrent to dark current was measured for the $\mathrm{Ga}_{2} \mathrm{O}_{3}$ on quartz without and with $5 \mathrm{~nm} \mathrm{Ag}$ catalyst (Fig. 13b) at $10 \mathrm{~V}$ for $\mathrm{Ga}_{2} \mathrm{O}_{3}$ with $\mathrm{Ag}$ catalyst were almost 38.3 compared to the $\mathrm{Ag}$-free $\mathrm{Ga}_{2} \mathrm{O}_{3}$ which was 4.55. Table 2 shows the performance of the developed $\beta$ - $\mathrm{Ga}_{2} \mathrm{O}_{3}$ device compared to others. 


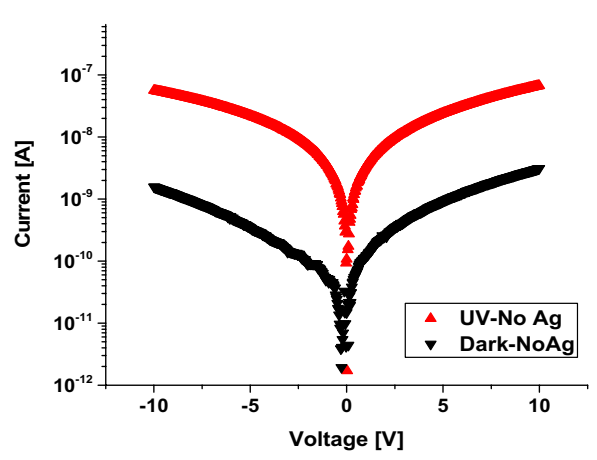

a

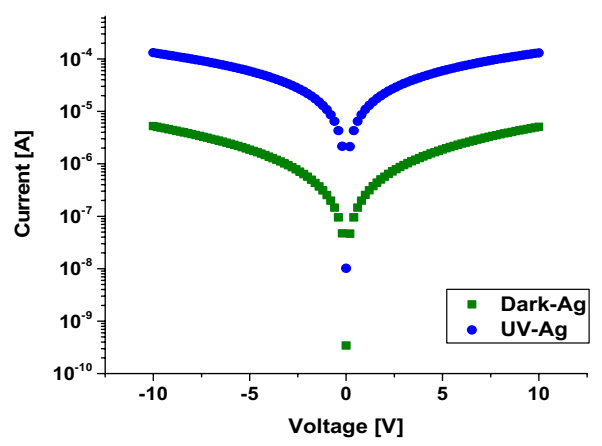

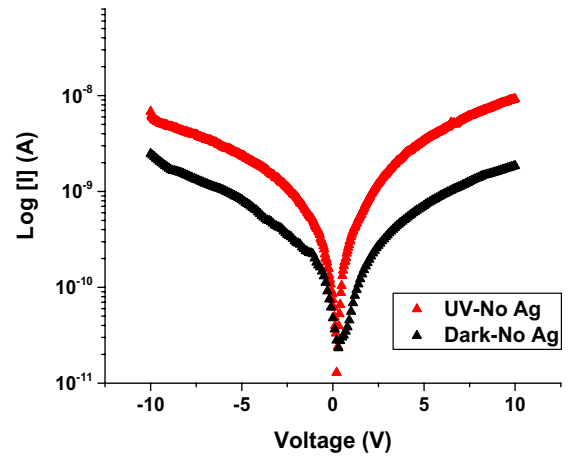

b

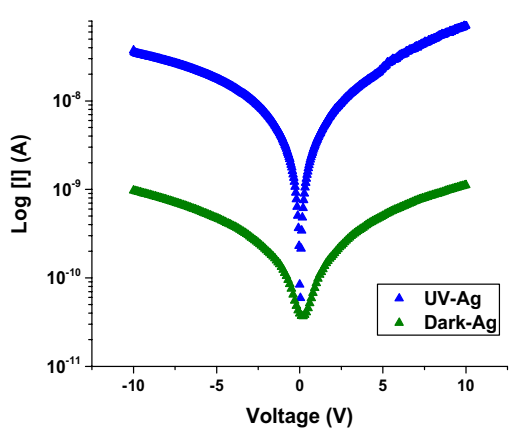

Figure 12. Semi-logarithmic plots of current density for $\mathrm{Au} / \beta-\mathrm{Ga}_{2} \mathrm{O}_{3} / \mathrm{Au} \mathrm{MSM}$ without and with $\mathrm{Ag}$ catalyst versus applied voltage characteristics at $10 \mathrm{~V}$ without and with $\mathrm{UV}$ illumination. $(\mathbf{a}, \mathbf{c})$ with sputtered $\mathrm{Au}$ metal contacts $(\mathbf{b}, \mathbf{d})$ with mesh Au metal contacts.

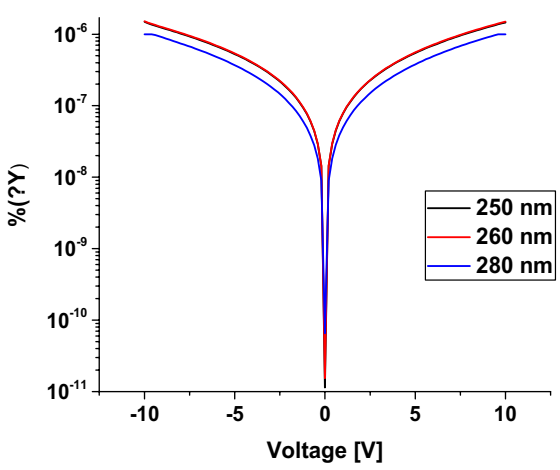

a

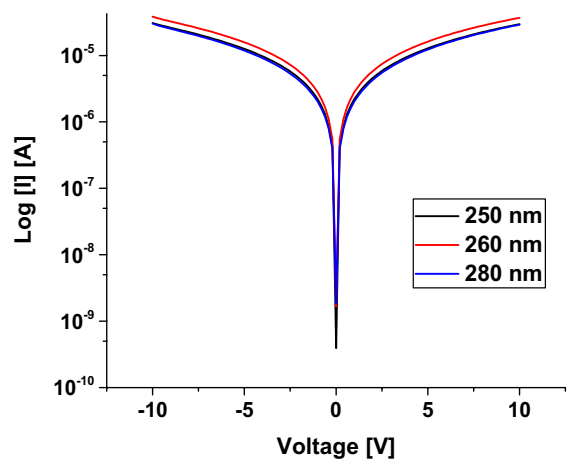

b

Figure 13. (a) semi-logarithmic plot of current-voltage for $\mathrm{Au} / \mathrm{\beta}-\mathrm{Ga}_{2} \mathrm{O}_{3} / \mathrm{Au} \mathrm{MSM}$ with $\mathrm{UV}$ illumination at 10 Vat different wavelengths such as $250 \mathrm{~nm}, 260 \mathrm{~nm}$ and $280 \mathrm{~nm}$. (a) without catalyst (b) with Ag catalyst.

Demonstration of UV photodetector responsivity based on $\mathrm{Ga}_{2} \mathrm{O}_{3}$ nanowire without and with $\mathrm{Ag}$ catalyst was examined (Fig. 14). The responsivity of $\mathrm{Ga}_{2} \mathrm{O}_{3}$ on quartz with $\mathrm{Ag}$ catalyst was higher than the one without catalyst approximately by 1.5 order of magnitude. In addition, responsivity curve measurements were taken using a XeHg lamp coupled to a monochromator to obtain a responsivity curve, as well as the responsivity at solar wavelengths. This data is shown in Fig. 14, which shows a larger response over a broad range of wavelengths. The solar-range response $(>300 \mathrm{~nm})$ is significant in both cases, however the relative responsivity in the Ag sample is about 3-5 times larger below the peak at $260 \mathrm{~nm}$. To qualify a device's solar blindness, the solar-UV rejection ratio is typically used ${ }^{19}$, which in this case we define as the response at $320 \mathrm{~nm}$, which is near the edge of the solar band, versus the response at $260 \mathrm{~nm}$. For the Ag sample, the solar-UV rejection ratio is about 50 , for the sample without $\mathrm{Ag}$ the rejection ratio is closer to 100. 


\begin{tabular}{|l|l|l|l|l|}
\hline \multirow{2}{*}{ Device structure } & \multicolumn{2}{|l|}{ MSM } & & \\
\cline { 2 - 3 } & No Ag & $\mathbf{5 ~ n m ~ A g}$ & NW network & MSM \\
\hline Fabrication method & Oxidation/vaporization & CVD & MOCVD \\
\hline Electrode & $\mathrm{Cr} / \mathrm{Au}$ & $\mathrm{Au}$ & $\mathrm{Au}$ \\
\hline Light of detection $(\mathrm{nm})$ & $190-400$ & $290-340$ & $255-260$ \\
\hline $\mathrm{I}_{\text {Photo }} / \mathrm{I}_{\text {Dark }}$ & $4.55 @ 10 \mathrm{~V}$ & $38.3 @ 10 \mathrm{~V}$ & $50 @ 10 \mathrm{~V}$ & 4.67 \\
\hline Year & 2019 & 2016 & 2015 \\
\hline Reference & This work & 17 & 18 \\
\hline
\end{tabular}

Table 2. Summary of $\beta-\mathrm{Ga}_{2} \mathrm{O}_{3}$ device performance of present device and other previously reported UV PDs.

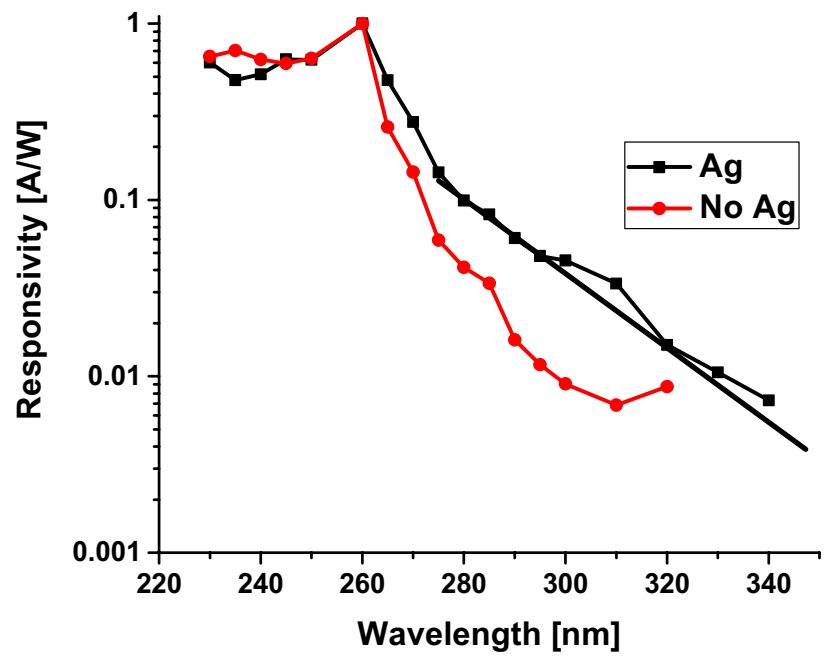

Figure 14. Responsivity vs different wavelengths for $\mathrm{Ga}_{2} \mathrm{O}_{3}$ without and with the presence of Ag catalyst.

When the incident UV light on the surface of $\beta-\mathrm{Ga}_{2} \mathrm{O}_{3}$ nanowire in the presence of $\mathrm{Ag}$ NPs is below $320 \mathrm{~nm}$, the impact of interband transitions on Ag NPs occurs ${ }^{20-22}$. Hence, highly energetic hot electrons of Ag NPs will be excited from the $4 \mathrm{~d}$ and $5 \mathrm{sp}$ bands. This property could enhance the performance of $\mathrm{Ga}_{2} \mathrm{O}_{3}$ in ultra-violet detection due to the presence of Ag NPs, which would lead to the observed shallower tail in the responsivity curve.

Transient photocurrent. The transient response of the photodetector was measured by opening and closing a shutter on a broad spectrum UV light source (Fig. 15). $\mathrm{Ga}_{2} \mathrm{O}_{3}$ on quartz with an Ag catalyst showed a fasttransient response due to enhanced carrier transport. When the UV illumination was turned on, there was a large increase in the photocurrent. Due to the surface plasmonic effect of $\mathrm{Ag}$ NPs at the surface of $\mathrm{Ga}_{2} \mathrm{O}_{3} \mathrm{NWs}$, the absorption of photon is highly enhanced ${ }^{14}$, leading to more photoexcited carriers transport and collection at the contacts. On the other hand, when the UV light is turned off, the free electrons will recombine with holes very rapidly.

In $\mathrm{Ga}_{2} \mathrm{O}_{3}$ without an Ag catalyst, by turning the light on and off, a relatively slow response occurred in the device turning on. This slow response was attributed to the traps and surface states of oxygen generated at the surface of gallium oxide ${ }^{23}$. A longer tail in the photocurrent occurred when the light was turned off due to the reduction of charge carrier recombination as a result of captured hole-trap states. Hence, a longer recovery time is required because of the diffusion of oxygen molecules. The average rise time (from 10 to $90 \%$ of maximum photocurrent) and fall time (from 90 to $10 \%$ of maximum photocurrent) are $1.12 \mathrm{~s}$ and $2.0 \mathrm{~s}$ for Ag-free $\mathrm{Ga}_{2} \mathrm{O}_{3}$ and $0.33 \mathrm{~s}$ and $2.2 \mathrm{~s}$ for $\mathrm{Ga}_{2} \mathrm{O}_{3}$ in the presence of Ag. Hence, $\mathrm{Ag}$ NPs presence enhances faster rise time, but similar fall time. In $\mathrm{Ga}_{2} \mathrm{O}_{3}$ with an Ag catalyst, silver nanoparticles enhance the adsorption of light in the sample, and thus and desorption of oxygen molecules. When Ag NPs were excited by the UV light, each nanoparticle will generate a light-induced dipole ${ }^{24}$. Hence, the dipole-diploe interaction of Ag nanoparticles influences each nanoparticle and those nearby it.

Silver (Ag) nanoparticles (NPs) catalyzes the growth of $\mathrm{Ga}_{2} \mathrm{O}_{3}$ nanowires. Based on the detailed characterization performed on the oxidation of liquid Gallium $(\mathrm{Ga})$ in a quartz crucible, the presence or absence of an Ag thin film on quartz substrate could help explain the growth mechanism. The growth mechanism is summarized in Fig. 16. Ga is oxidized and forms a solid phase of gallium (III) oxide $\left(\mathrm{Ga}_{2} \mathrm{O}_{3}\right)(\mathrm{Eq} .1)^{25,26}$. Then, this $\mathrm{Ga}_{2} \mathrm{O}_{3}$ is reduced by liquid metallic gallium and forms a gas phase of gallium suboxide $\left(\mathrm{Ga}_{2} \mathrm{O}\right)$ (Eq. 2$)^{27}$. 


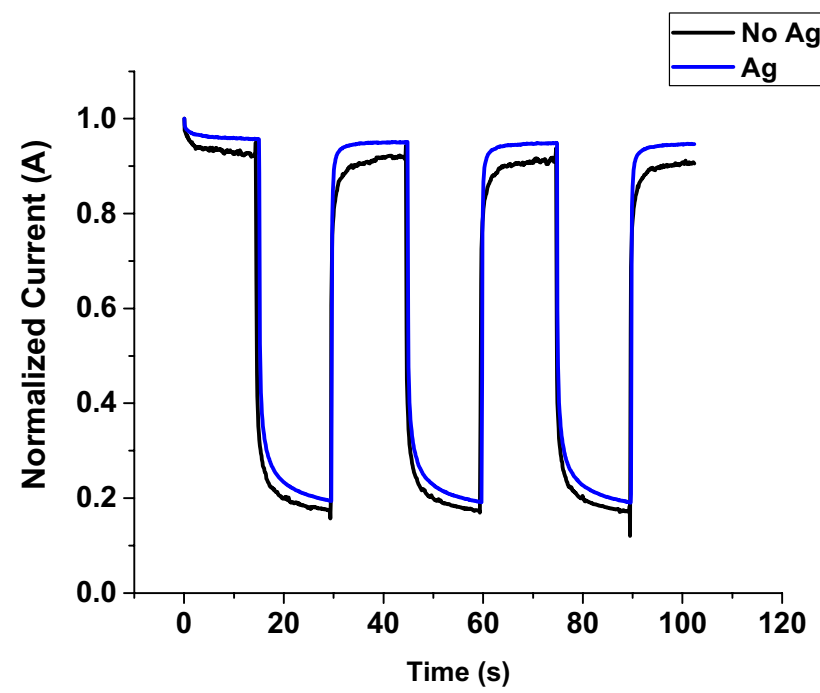

Figure 15. Transient response of the UV photodetector fabricated based on $A u / \beta-\mathrm{Ga}_{2} \mathrm{O}_{3} / \mathrm{Au} \mathrm{MSM}$ at $5 \mathrm{~V}$ without and with Ag catalyst.
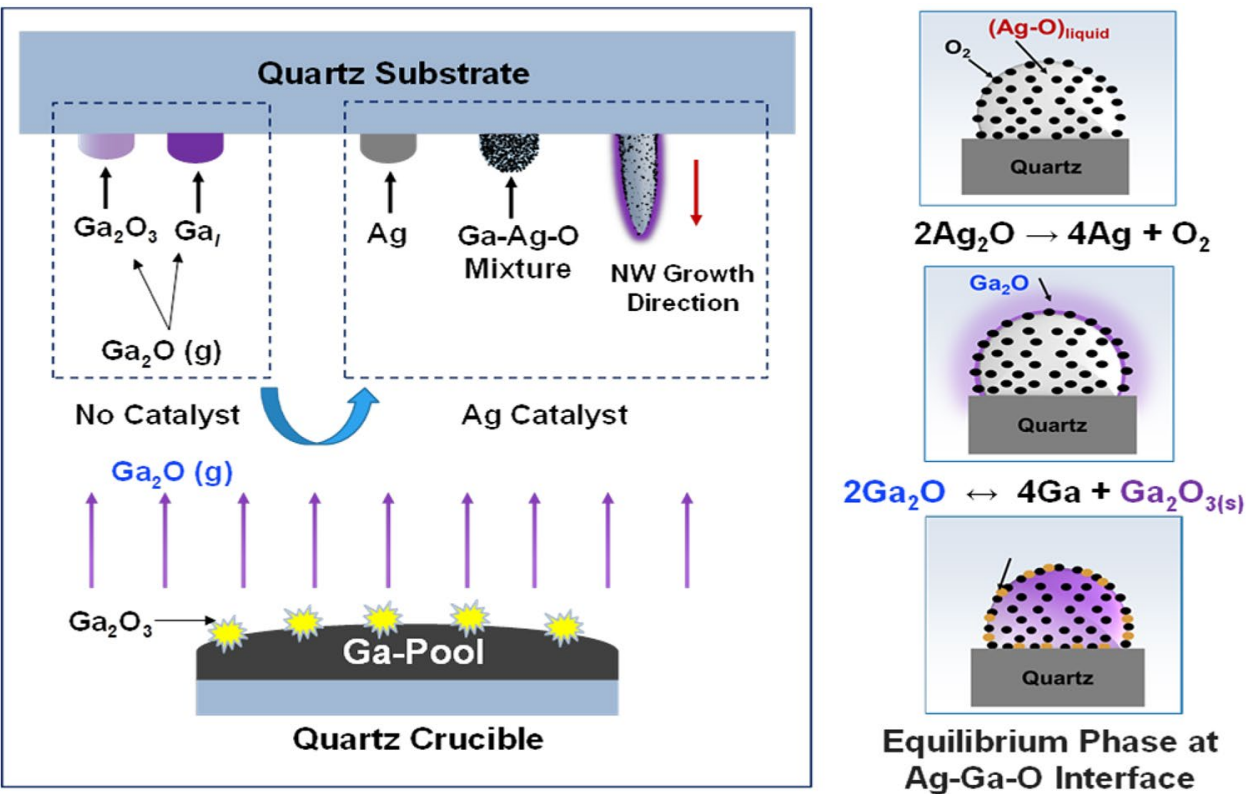

\section{Equilibrium Phase at Ag-Ga-O Interface}

Figure 16. The growth mechanism of $\mathrm{Ga}_{2} \mathrm{O}_{3} \mathrm{NWs}$ on a quartz substrate coated with $5 \mathrm{~nm} \mathrm{Ag} \mathrm{film} \mathrm{(facing}$ downward). A pool of liquid $\mathrm{Ga}$ is heated in a quartz crucible that sits under the quartz substrate with $\sim 10 \mathrm{~mm}$ gap.

The $\mathrm{Ga}_{2} \mathrm{O}$ gas phase gets transported to cooler regions and decomposes to liquid gallium and $\mathrm{Ga}_{2} \mathrm{O}_{3}{ }^{28,29}$, leading to a vapor-liquid-solid (VLS) growth mechanism. In the presence of Ag catalyst, more solid phase of $\mathrm{Ga}_{2} \mathrm{O}_{3}$ is formed.

$$
\begin{aligned}
2 \mathrm{Ga}+(3 / 2) \mathrm{O}_{2} & \rightarrow \mathrm{Ga}_{2} \mathrm{O}_{3(\mathrm{~s})} \\
\mathrm{Ga}_{2} \mathrm{O}_{3(\mathrm{~s})}+4 \mathrm{Ga}_{(\mathrm{l})} & \leftrightarrow 3 \mathrm{Ga}_{2} \mathrm{O}_{(\mathrm{g})} \\
\mathrm{Ga}_{2} \mathrm{O}_{(\mathrm{g})}+\mathrm{O}_{2(\mathrm{~g})} & \rightarrow \mathrm{Ga}_{2} \mathrm{O}_{3(\mathrm{~s})}
\end{aligned}
$$

The growth kinetics and the mechanism of incorporation of Ag catalyst to enhance denser and longer $\beta-\mathrm{Ga}_{2} \mathrm{O}_{3}$ nanowires can be explained using several factors that boost the presence of oxygen in the system. The dewetting 


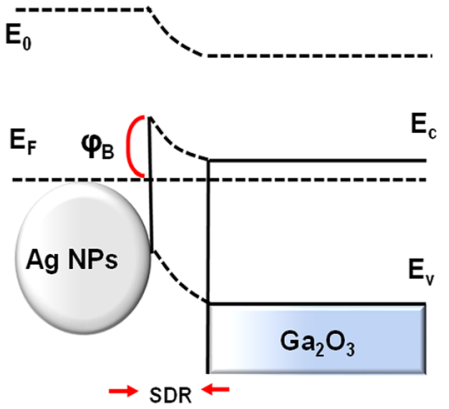

a
UV Illumination $<320 \mathrm{~nm}$

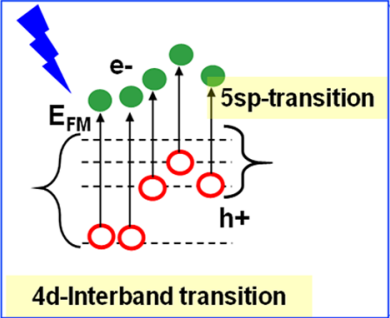

4d-Interband transition

Figure 17. Energy band diagram at the interface of $\mathrm{Ag} \mathrm{NPs}$ and $\mathrm{Ga}_{2} \mathrm{O}_{3} \mathrm{NWs}$. (a) In dark condition, a localized Schottky barrier exists due to the difference in work-function. (b) Under UV illumination, the interband transition in Ag NPs enhances the photosensitivity of the UV detection and more photo-generated holes of $\mathrm{Ga}_{2} \mathrm{O}_{3}$ NWs migrate to the surface by band bending.

of Ag thin films play a critical role in increasing the density of Ag NPs. As the film starts dewetting, the density of Ag NPs increases due to thermal and self-diffusion effects. At higher temperatures above $200{ }^{\circ} \mathrm{C}$, silver oxide decomposes into solid phase of $\mathrm{Ag}$ and oxygen molecules $\left(\mathrm{O}_{2}\right)$, which will be partially dissolved in $\mathrm{Ag}^{30}$. In addition, the solubility of $\mathrm{O}_{2}$ in solid $\mathrm{Ag}^{31}$ is much higher than the solubility of oxygen in liquid $\mathrm{Ga}^{26}$. Moreover, $\mathrm{O}_{2}$ solubility in $\mathrm{Ag}$ is significantly increased by increasing the temperature at fixed pressure. For instance, the solubility of $\mathrm{O}_{2}$ in $\mathrm{Ag}$ is $38.1 \mathrm{ppm}$ at $800{ }^{\circ} \mathrm{C}$ and $3000 \mathrm{ppm}$ at $1000^{\circ} \mathrm{C}$ at 1 bar of $\mathrm{O}_{2}$ pressure ${ }^{32}$. Consequently, oxygen from the furnace atmosphere is dissolved in $\mathrm{Ag}$ film. Consequently, there is an availability of oxygen that enhances the growth of $\mathrm{Ga}_{2} \mathrm{O}_{3}$. Furthermore, the enthalpy of formation of the oxidation of $\mathrm{Ga}$ is much more negative than that of the oxidation of $\mathrm{Ag}$, at all temperatures. This shows that the spontaneous nucleation of $\mathrm{Ga}_{2} \mathrm{O}_{3}$ begins to occur on $\mathrm{Ag}-\mathrm{Ga}-\mathrm{O}$ liquid mixture, where $\mathrm{Ga}$ strips the dissolved $\mathrm{O}_{2}$ away from $\mathrm{Ag}$ islands that form after dewetting.

On the Ag coated quartz, the vapor phase of gallium suboxide $\left(\mathrm{Ga}_{2} \mathrm{O}\right)$ spontaneously separates into $\mathrm{Ga}_{2} \mathrm{O}_{3}$ and liquid $\mathrm{Ga}$ (Eq. 2) or reacts with $\mathrm{O}_{2}$ dissolved in $\mathrm{Ag}$ to form $\mathrm{Ga}_{2} \mathrm{O}_{3}$ (Eq. 1). The $\mathrm{Ga}_{2} \mathrm{O}$ vapor coats the mixture of $\mathrm{Ag}$ and $\mathrm{Ga}_{2} \mathrm{O}_{3}$ spontaneously to enhance more $\mathrm{Ga}_{2} \mathrm{O}_{3}$ formation at the surface of Ag. These $\mathrm{Ga}_{2} \mathrm{O}_{3}$ molecules could dissolve in $\mathrm{Ag}$ and move to the interface of $\mathrm{Ag}$ and $\mathrm{Ga}_{2} \mathrm{O}_{3}$, leading to an equilibrium phase of $\mathrm{AgGaO}_{\mathrm{x}}$ $\left(\mathrm{Ag}-\mathrm{Ga}-\mathrm{O}\right.$ phase diagram No. 209084) ${ }^{33}$. At $800^{\circ} \mathrm{C}$, oxygen's solubility in $\mathrm{Ag}$ is highly increased and it contributes to enhanced $\mathrm{Ga}_{2} \mathrm{O}_{3}$ nucleation. However, at higher temperature $\left(1000^{\circ} \mathrm{C}\right)$, the growth saturates and gallium (III) oxide $\left(\mathrm{Ga}_{2} \mathrm{O}_{3}\right)$ nanowires are enhanced due to higher $\mathrm{O}_{2}$ solubility. Therefore, a continuous supply of $\mathrm{Ga}_{2} \mathrm{O}$ and $\mathrm{O}_{2}$ in the presence of $\mathrm{Ag}$ would increase the growth of $\mathrm{Ga}_{2} \mathrm{O}_{3}$.

Ag NPs enhances the photosensitivity of $\mathrm{Ga}_{2} \mathrm{O}_{3}$ nanowires. Photo-sensitivity at the interface of $\mathrm{Ag}$-free NPs and $\mathrm{Ga}_{2} \mathrm{O}_{3}$ nanowires. The experimental results of the two types of fabricated devices (Ag-free $\mathrm{Ga}_{2} \mathrm{O}_{3}$ on quartz and $\mathrm{Ga}_{2} \mathrm{O}_{3}$ on quartz in the presence of $\mathrm{Ag}$ ). Generally, the trap states of oxygen generated at the surface of gallium oxide have a large impact on device performance ${ }^{23}$. In Ag-free $\mathrm{Ga}_{2} \mathrm{O}_{3}$ on quartz, the results show weaker response compare to that of $\mathrm{Ga}_{2} \mathrm{O}_{3}$ on quartz in the presence of Ag. Under illumination, the Ag-free $\mathrm{Ga}_{2} \mathrm{O}_{3}$ nanowires had a smaller surface depletion layer due to the insufficient volume of ionized oxygen; hence, most of the photogenerated electron-hole pairs could recombine at the $\mathrm{Ga}_{2} \mathrm{O}_{3}$ nanowire crystal defects, resulting low response photocurrent.

Photo-sensitivity of $\mathrm{Ag} \mathrm{NPs}$ at the interface of $\mathrm{Ga}_{2} \mathrm{O}_{3}$ nanowires. The experimental results of $\mathrm{Ga}_{2} \mathrm{O}_{3}$ on quartz in the presence of Ag nanoparticles are explicitly explained using schematics of the interface of the materials in the dark and under UV illumination. To illustrate the photodetection mechanism, the energy band diagrams of a $\beta-\mathrm{Ga}_{2} \mathrm{O}_{3}$ photodetector in the presence of $\mathrm{Ag}$ nanoparticles are plotted in Fig. 17.

In $\beta-\mathrm{Ga}_{2} \mathrm{O}_{3}$ nanowires coated with $\mathrm{Ag} \mathrm{NPs}$, the work function $\left(\varphi_{\mathrm{Ga} 2 \mathrm{O} 3}\right)$ and electron affinity $\left(\chi_{\mathrm{Ga}_{2} \mathrm{O} 3}\right)$ of $\beta-\mathrm{Ga}_{2} \mathrm{O}_{3}$ are $4.11 \pm 0.05 \mathrm{eV}$ and $4.00 \pm 0.05 \mathrm{eV}^{34}$, respectively, which is lower than the work function of $\mathrm{Ag}$ $\left(\varphi_{\mathrm{Ag}}=4.26 \mathrm{eV}\right)^{35}$. This causes a Schottky barrier $\left(\varphi_{\mathrm{B}}=\varphi_{\mathrm{Ag}}-\chi_{\mathrm{Ga} 2 \mathrm{O} 3}=0.26 \mathrm{eV}\right)$ to form. The Schottky barrier prevents the movement of electrons from $\mathrm{Ag}$ to $\mathrm{Ga}_{2} \mathrm{O}_{3}$. Consequently, a localized Schottky junction will form a charge depletion region at the interface of $\mathrm{Ag}$ NPs and $\beta-\mathrm{Ga}_{2} \mathrm{O}_{3}$ nanowires. In dark condition, $\mathrm{Ag}$ NPs deplete the carriers at the interface. As the width of the depletion layer increases, the depletion region close to Ag NPs increases. Therefore, there is a large depletion width at the interface between Ag NPs and $\beta-\mathrm{Ga}_{2} \mathrm{O}_{3}$ nanowires. The dark current of the photodetector in $\beta-\mathrm{Ga}_{2} \mathrm{O}_{3}$ in the presence of $\mathrm{Ag}$ NPs thus decreases (Fig. 17a).

Under UV illumination, when the photon energy is larger than the bandgap of $\mathrm{Ga}_{2} \mathrm{O}_{3}$, electron-hole pairs are generated $\left[h v \rightarrow \mathrm{e}^{-}+h^{+}\right]$. Hence electrons move from the valence band to conduction band, leaving behind a hole. 
Based on traps and photoconduction mechanism, photogenerated carriers instantly increase the carrier density in $\beta-\mathrm{Ga}_{2} \mathrm{O}_{3}$ nanowires and improve the photocurrent response. Oxygen molecules are absorbed on the surface of $\mathrm{Ga}_{2} \mathrm{O}_{3}$ and are ionized by free electrons $\left[\mathrm{O}_{2}+\mathrm{e}^{-} \rightarrow \mathrm{O}_{2}^{-}[\mathrm{ad}]\right]^{33,36}$. The holes migrate to the surface, accumulate, recombine with adsorbed ionized oxygen and form free oxygen molecules from the surface $\left[\mathrm{O}_{2}^{-}[\mathrm{ad}]+\mathrm{h}^{+} \rightarrow \mathrm{O}_{2}\right]$. The remaining electrons become the majority carriers that contribute to an increase in the photocurrent by generation and recombination until reaching an equilibrium level. If the incident UV light on $\beta-\mathrm{Ga}_{2} \mathrm{O}_{3}$ in the presence of Ag NPs is below $320 \mathrm{~nm}$, the effect of interband transitions on Ag NPs at the interface of $\beta-\mathrm{Ga}_{2} \mathrm{O}_{3}$ nanowires allows the transition of highly energetic hot electrons of Ag NPs which excite from the 4d and 5sp bands ${ }^{20-22}$. These hot electrons surmount the small Schottky barrier height and form local band bending downward on $\mathrm{Ga}_{2} \mathrm{O}_{3}$ side to enable the electron transfer from $\mathrm{Ag}$ NPs to the conduction band of $\mathrm{Ga}_{2} \mathrm{O}_{3}$ nanowires. Consequently, there is a higher electron density in $\mathrm{Ga}_{2} \mathrm{O}_{3}$ nanowires with Ag NPs compared to Ag-free $\mathrm{Ga}_{2} \mathrm{O}_{3}$ nanowires, leading to a higher photocurrent and hence a more photo-sensitive photodetector (Fig. 17b).

In addition, the efficiency of the device is highly influenced by the presence of oxygen generated at the surface of $\mathrm{Ga}_{2} \mathrm{O}_{3}$ nanowires, causing trap states ${ }^{23}$. These states at the surface of $\mathrm{Ga}_{2} \mathrm{O}_{3}$ nanowires contains highly dense dangling bonds. Therefore, the surface of nanowires has higher sensitivity and better detection mechanism due to the large surface to volume ratio of nanowires and Ag NPs presence. It has been found that the photo-to-dark current ratio of nanowires $\left(2.33 \times 10^{-7} \mathrm{~A}\right)$ was higher than the that of thin film $\left(9.16 \times 10^{-8} \mathrm{~A}\right)^{37}$.

\section{Conclusion}

In brief, a $\beta-\mathrm{Ga}_{2} \mathrm{O}_{3}$ nanowires for UV photodetector with and without Ag catalyst has been proposed and demonstrated. Silver plays a critical role to enhance the growth mechanism of $\mathrm{Ga}_{2} \mathrm{O}_{3}$ nanowires due to its higher $\mathrm{O}_{2}$ solubility and diffusivity. The growth mechanism and characterization of $\mathrm{Ga}_{2} \mathrm{O}_{3}$ nanowires without and with $\mathrm{Ag}$ catalyst has been explained. It was found by SAED that the orientation of the nanowires is not affected by the use of Ag catalyst during growth. The ratio of photo-to-dark current without and with Ag catalyst of 4.55 and 38.3, respectively, was achieved, leading to more sensitive detection of UV light. The responsivity curve shows that $\mathrm{Ga}_{2} \mathrm{O}_{3}$ nanowires in the presence of $\mathrm{Ag}$ has a cut-off at $320 \mathrm{~nm}$ due to the existence of mid-gap state. Hence, the simplicity of this fabrication method suggests a promising device for sensing UV light, particularly for mass production. Our results could offer a promising technique to grow nanowires with high sensitivity and spectral selectivity to UV light.

Received: 26 June 2020; Accepted: 20 November 2020

Published online: 08 December 2020

\section{References}

1. González-Posada, F., Den Hertog, R. S. M. \& Monroy, E. Room-temperature photodetection dynamics of single GaN nanowires. Nano Lett. 12, 172-176. https://doi.org/10.1021/nl2032684 (2012).

2. Pearton, S. J. et al. A review of $\mathrm{Ga}_{2} \mathrm{O}_{3}$ materials, processing, and devices. Appl. Phys. Rev. 5, 011301. https://doi.org/10.1063/1.50069 41 (2018).

3. Kaya, A. $\beta$-Ga2O3 films grown via oxidation of GaAs substrates and their device demonstrations. Wide Bandgap Power Devices and Applications II SPIE (2017).

4. Zhang, Y. Y., Wu, J., Aagesen, M. \& Liu, H. Y. III-V nanowires and nanowire optoelectronic devices. J. Phys. D Appl. Phys. https:// doi.org/10.1088/0022-3727/48/46/463001 (2015).

5. Dai, X. et al. GaAs/AlGaAs nanowire photodetector. Nano Lett. 14, 2688-2693. https://doi.org/10.1021/nl5006004 (2014).

6. Zhang, Z., Li, Q., Haque, S. S. \& Zhang, M. Far-field plasmonic resonance enhanced nanoparticle image velocimetry within a microchannel. Rev. Sci. Instrum. 82, 023117. https://doi.org/10.1063/1.3555341 (2011).

7. Soci, C. Z. A., Bao, X. Y., Kim, H., Lo, Y. \& Wang, D. Nanowire photodetectors. J. Nanosci. Nanotechnol. 3, 1430-1449 (2010).

8. Logeeswaran, V. J. et al. A perspective on nanowire photodetectors: current status, future challenges, and opportunities. IEEE J. Sel. Top. Quant. 17, 1002-1032. https://doi.org/10.1109/Jstqe.2010.2093508 (2011).

9. Ghobadi, N. Band gap determination using absorption spectrum fitting procedure. Int. Nano Lett. 3, 2. https://doi.org/10.1186/22285326-3-2 (2013).

10. Han, C. Q. et al. Preparation of $\mathrm{Ag} / \mathrm{Ga}_{2} \mathrm{O}_{3}$ nanofibers via electrospinning and enhanced photocatalytic hydrogen evolution. Int. J. Hydrog. Energy 42, 19913-19919. https://doi.org/10.1016/j.ijhydene.2017.06.076 (2017).

11. Sudheer Kumar, B. S. G., R. Singh. Growth and characterization of nickel catalyzed gallium oxide nanowires on sapphire substrate. Nano-Electron. Phys $\mathbf{5}$ (2013).

12. Kumar, M., Kumar, V. \& Singh, R. Diameter tuning of beta- $\mathrm{Ga}_{2} \mathrm{O}_{3}$ nanowires using chemical vapor deposition technique. Nanoscale Res. Lett. https://doi.org/10.1186/s11671-017-1915-1 (2017).

13. Kuo, C. L. \& Huang, M. H. The growth of ultralong and highly blue luminescent gallium oxide nanowires and nanobelts, and direct horizontal nanowire growth on substrates. Nanotechnology https://doi.org/10.1088/0957-4484/19/15/155604 (2008).

14. Yu, H., Peng, Y., Yang, Y. \& Li, Z.-Y. Plasmon-enhanced light-matter interactions and applications. NPJ Comput. Mater. 5, 45. https ://doi.org/10.1038/s41524-019-0184-1 (2019)

15. Shao, D. L. et al. High responsivity, fast ultraviolet photodetector fabricated from $\mathrm{ZnO}$ nanoparticle-graphene core-shell structures. Nanoscale 5, 3664-3667. https://doi.org/10.1039/c3nr00369h (2013).

16. Pearton, S. J. et al. A review of $\mathrm{Ga}_{2} \mathrm{O}_{3}$ materials, processing, and devices. Appl. Phys. Rev. https://doi.org/10.1063/1.5006941 (2018).

17. Du, J. Y. et al. Highly sensitive and ultrafast deep UV photodetector based on a beta- $\mathrm{Ga}_{2} \mathrm{O}_{3}$ nanowire network grown by CVD. J. Phys. D Appl. Phys. https://doi.org/10.1088/0022-3727/49/42/425105 (2016).

18. Hu, G. C. et al. High gain $\mathrm{Ga}_{2} \mathrm{O}_{3}$ solar-blind photodetectors realized via a carrier multiplication process. Opt Express $23,13554-$ 13561. https://doi.org/10.1364/Oe.23.013554 (2015).

19. Xu, J., Zheng, W. \& Huang, F. Gallium oxide solar-blind ultraviolet photodetectors: a review. J. Mater. Chem. C 7, 8753-8770. https ://doi.org/10.1039/C9TC02055A (2019).

20. Aslam, U., Rao, V. G., Chavez, S. \& Linic, S. Catalytic conversion of solar to chemical energy on plasmonic metal nanostructures. Nat. Catal. 1, 656-665. https://doi.org/10.1038/s41929-018-0138-x (2018).

21. Alarcon, E. I., Griffith, M., \& Udekwu, K. I. Silver nanoparticle applications: In The Fabrication and Design of Medical and Biosensing Devices. https://doi.org/10.1007/978-3-319-11262-6 (2015). 
22. Kanika Arora, V. K., Mukesh Kumar. Silver plasmonic density tuned polarity switching and anomalous behaviour of high performance self-powered $\beta$-gallium oxide solarblind photodetector. Appl. Phys. Lett. (2018).

23. Weng, W. Y., Hsueh, T. J., Chang, S. J., Huang, G. J. \& Hsueh, H. T. A beta- $\mathrm{Ga}_{2} \mathrm{O}_{3}$ solar-blind photodetector prepared by furnace oxidization of GaN thin film. IEEE Sens. J. 11, 999-1003. https://doi.org/10.1109/Jsen.2010.2062176 (2011).

24. Chen, F. Y. \& Johnston, R. L. Plasmonic properties of silver nanoparticles on two substrates. Plasmonics 4, 147-152. https://doi. org/10.1007/s11468-009-9087-1 (2009).

25. Wang, Y. Z. et al. Properties and photocatalytic activity of beta- $\mathrm{Ga}_{2} \mathrm{O}_{3}$ nanorods under simulated solar irradiation. J. Nanomater. https://doi.org/10.1155/2015/191793 (2015).

26. Zinkevich, M. \& Aldinger, F. Thermodynamic assessment of the gallium-oxygen system. J. Am. Ceram. Soc. 87, 683-691. https:// doi.org/10.1111/j.1551-2916.2004.00683.x (2004).

27. Girija, K., Thirumalairajan, S., Mastelaro, V. R. \& Mangalaraj, D. Catalyst free vapor-solid deposition of morphologically different $\beta-\mathrm{Ga}_{2} \mathrm{O}_{3}$ nanostructure thin films for selective $\mathrm{CO}$ gas sensors at low temperature. Anal. Methods 8, 3224-3235. https://doi. org/10.1039/C6AY00391E (2016).

28. Butt, D. P., Park, Y. \& Taylor, T. N. Thermal vaporization and deposition of gallium oxide in hydrogen. J. Nucl. Mater. 264, 71-77. https://doi.org/10.1016/S0022-3115(98)00484-X (1999).

29. Kumar, S. \& Singh, R. Nanofunctional gallium oxide $\left(\mathrm{Ga}_{2} \mathrm{O}_{3}\right)$ nanowires/nanostructures and their applications in nanodevices. Phys. Status Solidi-R 7, 781-792. https://doi.org/10.1002/pssr.201307253 (2013).

30. Kesim, M. T., Yu, H., Sun, Y., Aindow, M. \& Alpay, S. P. Corrosion, oxidation, erosion and performance of Ag/W-based circuit breaker contacts: A review. Corros. Sci. 135, 12-34. https://doi.org/10.1016/j.corsci.2018.02.010 (2018).

31. Assal, J., Hallstedt, B. \& Gauckler, L. J. Thermodynamic assessment of the silver-oxygen system (vol 80, pg 3054, 1997). J. Am. Ceram. Soc. 81, 450-451 (1998).

32. Martienssen, W. W., Hans. Springer Handbook of Condensed Matter and Materials Data. Springer. https://doi.org/10.1007/3-54030437-1 (00/2005)

33. Soci, C. et al. ZnO nanowire UV photodetectors with high internal gain. Nano Lett. 7, 1003-1009. https://doi.org/10.1021/nl070 $111 x(2007)$.

34. Mohamed, M. et al. Schottky barrier height of Au on the transparent semiconducting oxide beta- $\mathrm{Ga}_{2} \mathrm{O}_{3}$. Appl. Phys. Lett. https:// doi.org/10.1063/1.4755770 (2012).

35. Chelvayohan, M. \& Mee, C. H. B. Work function measurements on (110), (100) and (111) Surfaces of Silver. J. Phys. C Solid State 15, 2305-2312. https://doi.org/10.1088/0022-3719/15/10/029 (1982).

36. Prades, J. D. et al. The effects of electron-hole separation on the photoconductivity of individual metal oxide nanowires. Nanotechnology https://doi.org/10.1088/0957-4484/19/46/465501 (2008).

37. Alhalaili, B., Bunk, R., Vidu, R. \& Islam, M. S. Dynamics contributions to the growth mechanism of $\mathrm{Ga}_{2} \mathrm{O}_{3}$ thin film and nws enabled by Ag catalyst. Nanomaterials 9, 1272 (2019).

\section{Author contributions}

B.A. and R.B. conceived the experiment(s). B.A., H.M., H.C. and R.B. conducted the experiment(s), R.B. and B.A. performed statistical analysis and figure generation. All authors reviewed the manuscript.

\section{Competing interests}

The authors declare no competing interests.

\section{Additional information}

Correspondence and requests for materials should be addressed to B.A.

Reprints and permissions information is available at www.nature.com/reprints.

Publisher's note Springer Nature remains neutral with regard to jurisdictional claims in published maps and institutional affiliations.

(c) (i) Open Access This article is licensed under a Creative Commons Attribution 4.0 International License, which permits use, sharing, adaptation, distribution and reproduction in any medium or format, as long as you give appropriate credit to the original author(s) and the source, provide a link to the Creative Commons licence, and indicate if changes were made. The images or other third party material in this article are included in the article's Creative Commons licence, unless indicated otherwise in a credit line to the material. If material is not included in the article's Creative Commons licence and your intended use is not permitted by statutory regulation or exceeds the permitted use, you will need to obtain permission directly from the copyright holder. To view a copy of this licence, visit http://creativecommons.org/licenses/by/4.0/.

(C) The Author(s) 2020 